\title{
Modified Ultra Wideband (UWB) Antipodal Vivaldi Antenna for $5 G$
}

\author{
Subuh Pramono ${ }^{1}$, Budi Basuki $S^{2}$, Tommi Hariyadi ${ }^{3}$ \\ ${ }^{1}$ Department of Electrical Engineering, Universitas Sebelas Maret Surakarta, Indonesia \\ ${ }^{2}$ Department of Electrical Engineering, Politeknik Negeri Semarang, Indonesia \\ ${ }^{3}$ Department of Electrical Engineering, Universitas Pendidikan Indonesia, Indonesia
}

\begin{tabular}{l} 
Article Info \\
\hline Article history: \\
Received Sep 20, 201 \\
Revised Dec 31, 201 \\
Accepted Aug 5, 201 \\
\hline Keyword: \\
5G \\
Bandwidth \\
Return loss (S11) \\
Ultra-Wideband \\
Vivaldi \\
VSWR
\end{tabular}

Article Info

ticle history:

Received Sep 20, 2017

Revised Dec 31, 2017

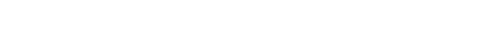

\begin{abstract}
This paper presents a half triangular Comb-shaped slits edge Antipodal Vivaldi Antenna (Comb-AVA) as compared to the conventional Antipodal Vivaldi Antenna (AVA) design. This proposed antenna covers $20-40 \mathrm{GHz}$ spectrum. This Comb-AVA antenna is designed for the $5 \mathrm{G}$ application which is addressed to cover a dualband $28 / 38 \mathrm{GHz}$ frequencies. A half triangular comb-shaped slits edge structure is employed to investigate its effects on antenna parameters. This proposed Comb-AVA occupies a $25 \times 8 \mathrm{~mm}^{2}$ of FR 4 substrate $\left(\varepsilon_{\gamma}=4.4, \tan \delta=0.02\right.$, thinkness $\left.1.6 \mathrm{~mm}\right)$. It has impedance bandwidth $\left(\mathrm{S}_{11} \leq-10 \mathrm{~dB}\right)$ along $20-40 \mathrm{GHz}$ spectrum and fractional bandwidth (FBW) $\geq 0.5$. It means that the bandwidth is categorized as ultra wideband (UWB). In addition, there is $11 \mathrm{~dB}$ refinement of return loss in the CombAVA design at $38 \mathrm{GHz}$ frequency. VSWR value is in range of 1.054 to 1.396. This proposed antena also has a wider angular width $(3 \mathrm{~dB})$ than the AVA. Higher directivity and gain is generated by Comb-AVA at $28 \mathrm{GHz}$. This proposed antenna has good performances and suitable for 5G application.
\end{abstract}

Copyright (C) 2018 Institute of Advanced Engineering and Science. All rights reserved.

\section{Corresponding Author:}

Subuh Pramono,

Department of Electrical Engineering,

Universitas Sebelas Maret Surakarta,

Surakarta, Indonesia.

Email: subuhpramono@gmail.com

\section{INTRODUCTION}

The millimeter wave communication is one of the potential solution platform for the next generation mobile wireless communication. Nowadays, mobile wireless communication has entered into the fifth generation (5G), many consortiums are still developing 5G standards. The most important requirements are wideband spectrum and higher frequency. Some frequencies have been proposed to be a candidate for the 5G spectrum, covering 6-100 GHz, i.e. 6-10 GHz, 27-29 GHz, 37-40 GHz, 50-52 GHz, 66-74 GHz, 81-86 GHz [9],[10]. The 5G antenna system that covers its wideband spectrum is continuously improved. Many types of microstrip antennas have been developed by researchers. The wideband antenna is used for the radio technology with a large bandwidth $(>500 \mathrm{MHz}$ ) or $20 \%$ of the center frequency (ultra-wideband $/ \mathrm{UWB} \geq 50 \%$ ) [2]. Recently, Tapered Slits Antenna/TSA (also called: Vivaldi antenna) has attracted attention due to their ultra-wideband bandwidth, high gain, and end-fire radiation patterns.

Vivaldi antenna was firstly introduced by P. J. Gibson [1]. This antenna has three main categories: Coplanar Vivaldi antenna, Antipodal Vivaldi antenna (AVA), Balanced Antipodal Vivaldi antenna (BAVA). The Coplanar Vivaldi antenna has two radiators on the one side of the dielectric substrate material which is pictured in Figure 1.a. Antipodal Vivaldi antenna, one radiator is printed on the top side and the other one on the bottom side of the dielectric substrate material. The Balanced Antipodal Vivaldi antenna comprised three 
radiators which are placed on the top, the middle, and the bottom side of the two dielectric substrate material and its structure is pictured in Figure 1.b. The Antipodal Vivaldi antenna (AVA) can reach wider bandwidth than Coplanar Vivaldi antenna.

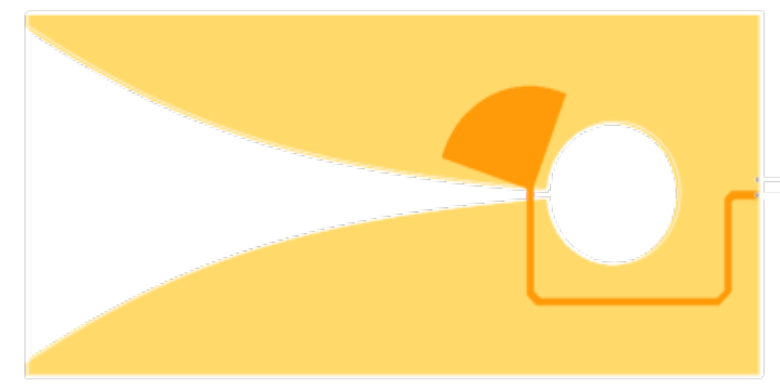

(a)

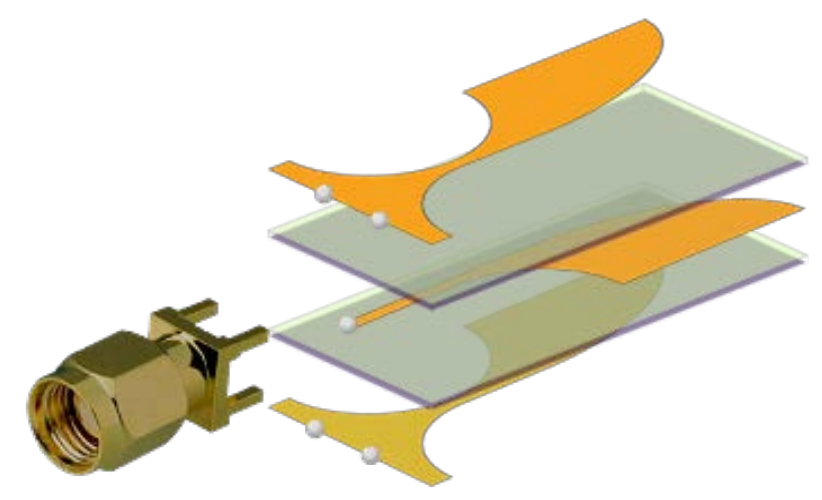

(b)

Figure 1. (a) Coplanar Vivaldi structure (b) AVA and BAVA structure

Several techniques have been developed to reduce the size of Vivaldi antenna and improve its high performance. Corrugation edges were used to reduce the size of the antenna with keeping the radiation patterns [3]. A modified Vivaldi antenna based on regular slits edge and loaded lens structure was presented in [4]. Palm Tree-Exponential Slits Edge Antipodal Vivaldi Antenna was developed for main lobe gain improvement [5]. The stepped slits line and patch, improving a wider bandwidth, has been introduced by [6]. The unequal half-circular slits in linearly tapered slits antenna, increasing the gain, was introduced by [7] [8].

This paper investigates comparison of a half triangular comb-shaped slits edge AVA (Comb-AVA) and conventional AVA (AVA). Antenna parameters are including VSWR, Return loss $\left(\mathrm{S}_{11}\right)$, gain, and radiation pattern of dualband $28 / 38 \mathrm{GHz}$ UWB $5 \mathrm{G}$ frequencies will be discussed. The impedance bandwidth of proposed Comb-AVA as defined by $\left|S_{11}\right| \leq-10 \mathrm{~dB}$ could be reached in range 20-40 GHz. This paper is arranged as Section I is introduction, Section II delivers the detail antenna design, Section III presents the result and analysis, and section IV is conclusion.

\section{ANTENNA DESIGN}

Complete geometrical design of half triangular comb-shaped slits edge AVA (Comb-AVA) and conventional AVA (AVA) is shown on Figure 2 and Figure 3, respectively. This proposed Comb AVA antenna occupies a $25 \times 8 \mathrm{~mm}^{2}$ of FR 4 substrate $\left(\varepsilon_{\gamma}=4.4\right.$, tan $\delta=0.02$, thinkness $\left.1.6 \mathrm{~mm}\right)$ and its dimensions are shown in Table 1 . The exponential taper is determined for inner edge by the rate $(\mathrm{r})$, point $\mathrm{A}\left(\mathrm{x}_{1}, \mathrm{y}_{1}\right)$, point $\mathrm{B}\left(\mathrm{x}_{2}, \mathrm{y}_{2}\right)$. It can be defined as

$$
y=C e^{r x}
$$




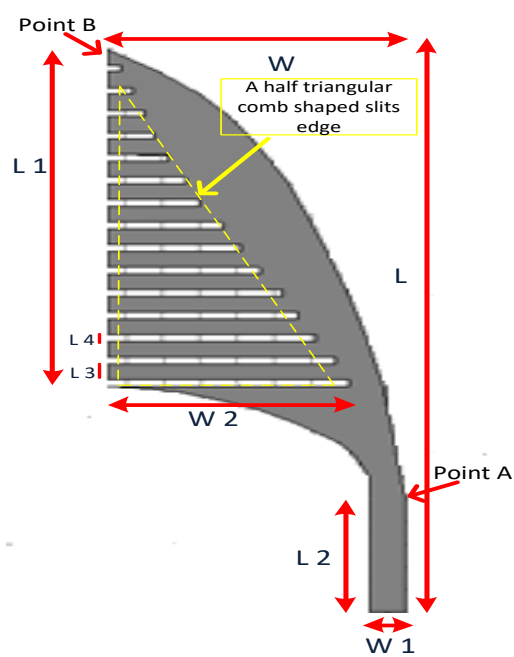

(a)

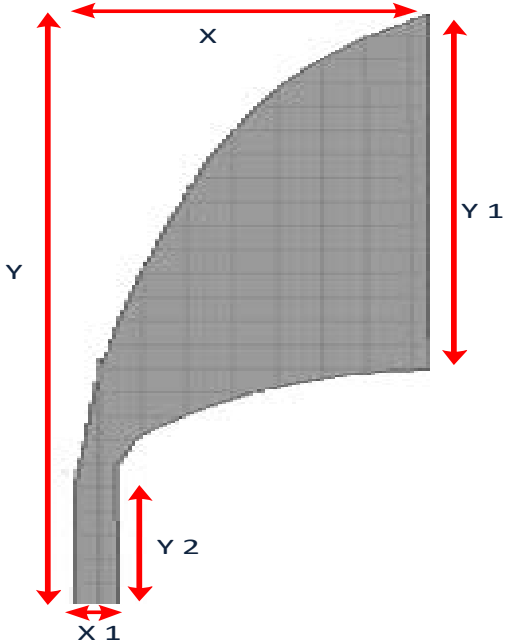

(b)

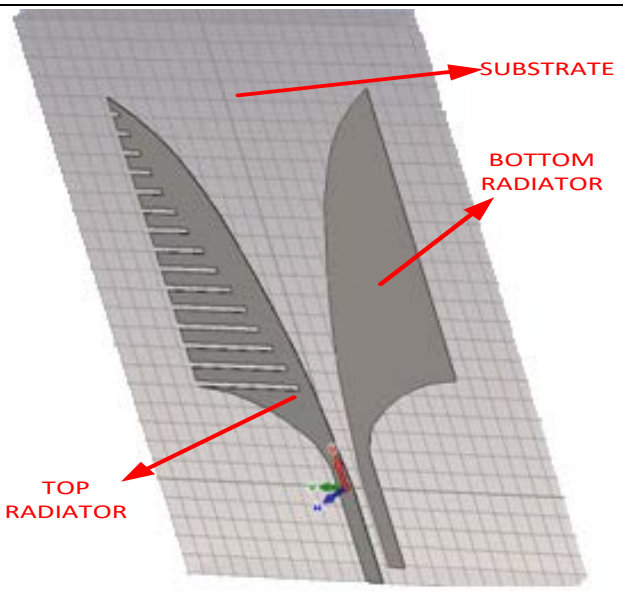

(c)

Figure 2. (a) Top side (comb-AVA) (b) bottom side (comb-AVA) (c) Complete geometrical (comb-AVA)

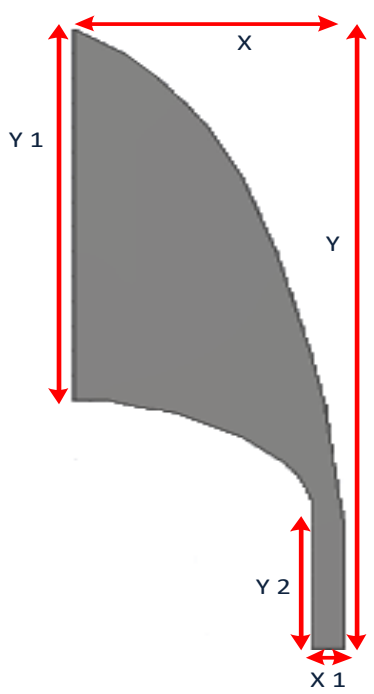

(a)

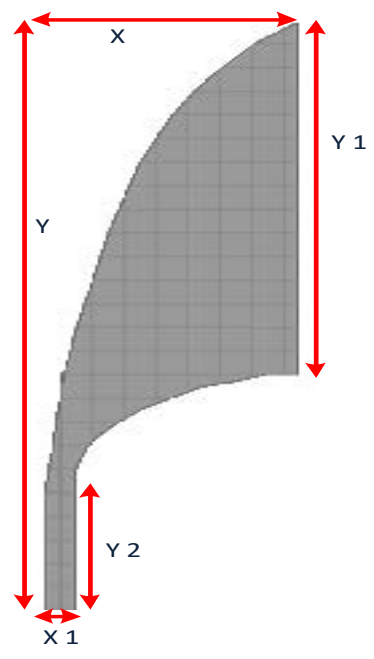

(b)

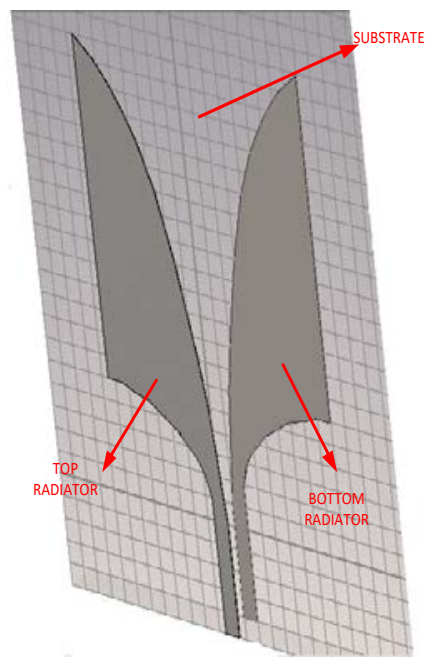

(c)

Figure 3. (a) Top side (AVA) (b) bottom side (AVA) (c) Complete geometrical (AVA) 
Table 1. Optimized Parameter of the Proposed Antenna

\begin{tabular}{ccccccccc}
\hline Parameter & $\mathrm{L}=\mathrm{Y}$ & $\mathrm{L} 1=\mathrm{Y} 1$ & $\mathrm{~L} 2=\mathrm{Y} 2$ & $\mathrm{~L} 3$ & $\mathrm{~L} 4$ & $\mathrm{~W}=\mathrm{X}$ & $\mathrm{W} 1=\mathrm{X} 1$ & W 2 \\
\hline Value $(\mathrm{mm})$ & 25 & 15 & 5 & 0.6 & 0.4 & 8 & 1 & 6.6 \\
\hline
\end{tabular}

\section{RESULTS AND ANALYSIS}

In this section, we will provide a discussion and analysis of half triangular comb-shaped slits effects in Antipodal Vivaldi antenna. Antenna parameters are including VSWR, return loss (S11), gain, and radiation pattern will be investigated. The proposed antenna was designed using CST studio suite.

\subsection{Return Loss $\left(\mathrm{S}_{11}\right)$}

Return loss $\left(\mathrm{S}_{11}\right)$ represents how match between an antenna and a transmission line. Return loss is related with ratio reflected power to incident power. Generally, expected return loss is less than $-10 \mathrm{~dB}$. It is related to Standing Wave Ratio (SWR) and reflection coefficient $(\Gamma)$. The return loss $\left(\mathrm{S}_{11}\right)$ covers in range of $-15.877 \mathrm{~dB}$ to $-31.188 \mathrm{~dB}$ at dualband $28 / 38 \mathrm{GHz} 5 \mathrm{G}$ frequencies. Figure 4 shows that the proposed half triangular comb-shaped slits edge Antipodal Vivaldi antenna (Comb-AVA) yields a better return loss than the conventional Vivaldi antenna (AVA) at a higher frequency (38 GHz). There is almost $10 \mathrm{~dB}$ refinement. Whereas, there is no significant improvement return loss at a lower frequency $(28 \mathrm{GHz}$ ) but it is still less than the return loss threshold (-10 dB), more detail is shown in Table 2. Impedance bandwidth is defined as separation between two $-10 \mathrm{~dB}$ return loss frequency. In addition, Comb-AVA bandwidth can be classified as an ultra-wideband because this antenna has fractional bandwidth (FBW) more than 0.5 which is denoted by

$$
\mathrm{FBW}=\frac{\mathrm{F}_{\mathrm{u}}-\mathrm{F}_{1}}{\mathrm{~F}_{\mathrm{c}}}
$$

$F_{u}$ is the highest frequency (40 GHz), $F_{l}$ is the lowest frequency (20 GHz), $F_{c}$ is the center frequency. When the center frequency is $28 \mathrm{GHz}$ that the FBW achieves 0.714 . Whereas, when we use center frequency 38 $\mathrm{GHz}$ that the FBW is 0.526 . For these two frequencies create $\mathrm{FBW} \geq 0.5$ are categorized an ultra wideband. More detail we can see in Table 3.

$$
\begin{aligned}
& \mathrm{FBW}_{28 \mathrm{GHz}}=\frac{\mathrm{F}_{\mathrm{u}}-\mathrm{F}_{1}}{\mathrm{~F}_{\mathrm{c}}}=\frac{40-20}{28}=0.714 \\
& \mathrm{FBW}_{38 \mathrm{GHz}}=\frac{\mathrm{F}_{\mathrm{u}}-\mathrm{F}_{1}}{\mathrm{~F}_{\mathrm{c}}}=\frac{40-20}{38}=0.526
\end{aligned}
$$

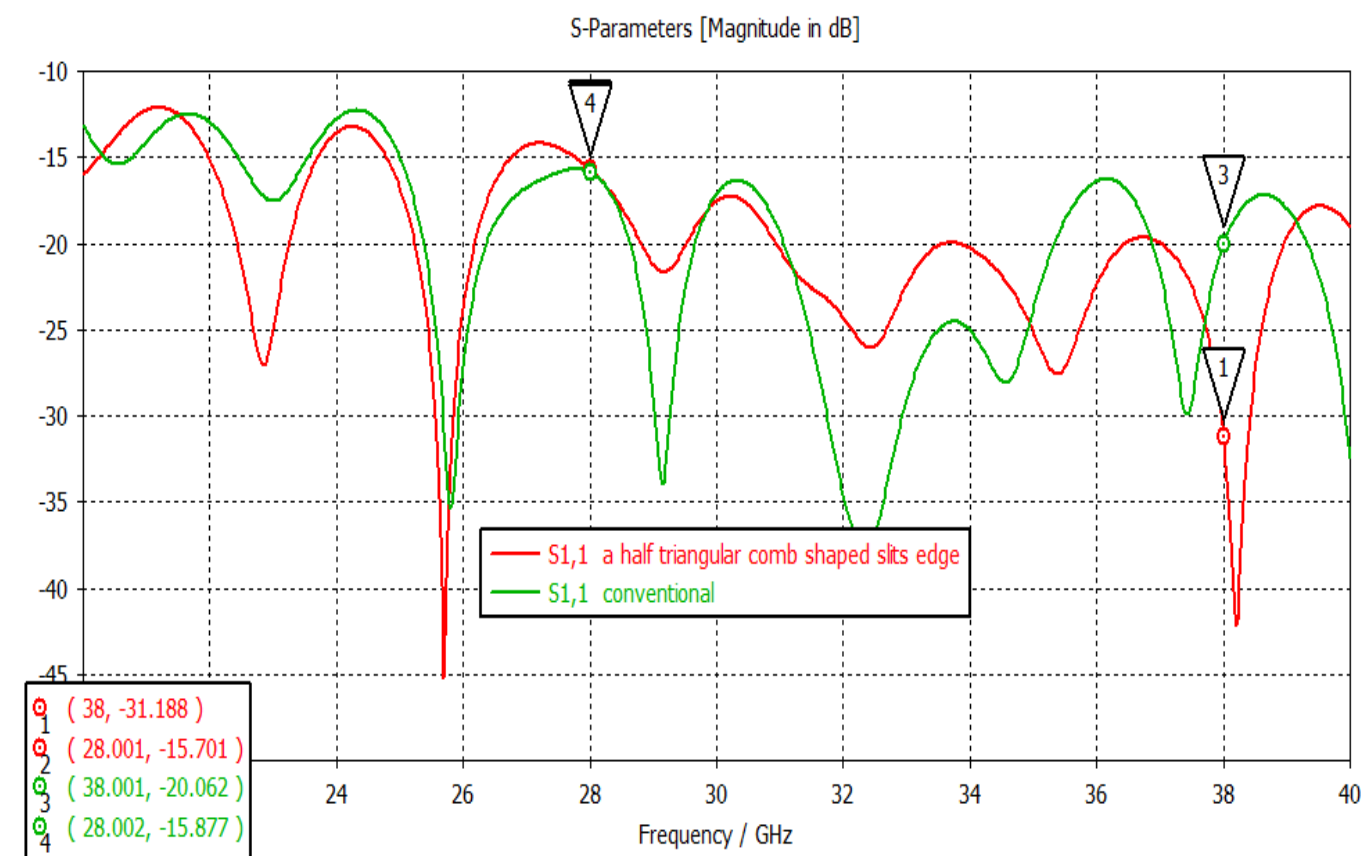

Figure 4. Return loss $\left(\mathrm{S}_{11}\right)$ profile 
Table 2. Return Loss $\left(\mathrm{S}_{11}\right)$

\begin{tabular}{ccc}
\hline $\mathrm{F}(\mathrm{MHz})$ & $\mathrm{S}_{11}$-conventional $(\mathrm{dB})$ & $\mathrm{S}_{11^{-}}$a half triangular comb-shaped slits edge $(\mathrm{dB})$ \\
\hline 28000 & -15.877 & -15.701 \\
38000 & -20.062 & -31.188 \\
\hline
\end{tabular}

Table 3. Impedance Bandwidth $\left(\mathrm{S}_{11} \leq-10 \mathrm{~dB}\right)$

\begin{tabular}{cccc}
\hline F (MHz) & BW Comb-AVA (MHz) & BW AVA (MHz) & FBW \\
\hline 28000 & $20-40 \mathrm{GHz}$ & $20-40 \mathrm{GHz}$ & 0.714 \\
38000 & $20-40 \mathrm{GHz}$ & $20-40 \mathrm{GHz}$ & 0.526 \\
\hline
\end{tabular}

\subsection{Voltage Standing Wave Ratio (VSWR)}

Figure 5 shows that VSWR of these antennas are in range of 1.054 to 1.3916 . The proposed CombAVA creates a better VSWR (1.054) than the AVA (1.2206) at the higher frequency (38 GHz). Meanwhile, both the Comb-AVA and the AVA produce a similar VSWR (1.3824 and 1.3916) at the lower frequency $(28 \mathrm{GHz})$, more detail is shown in Table 4.

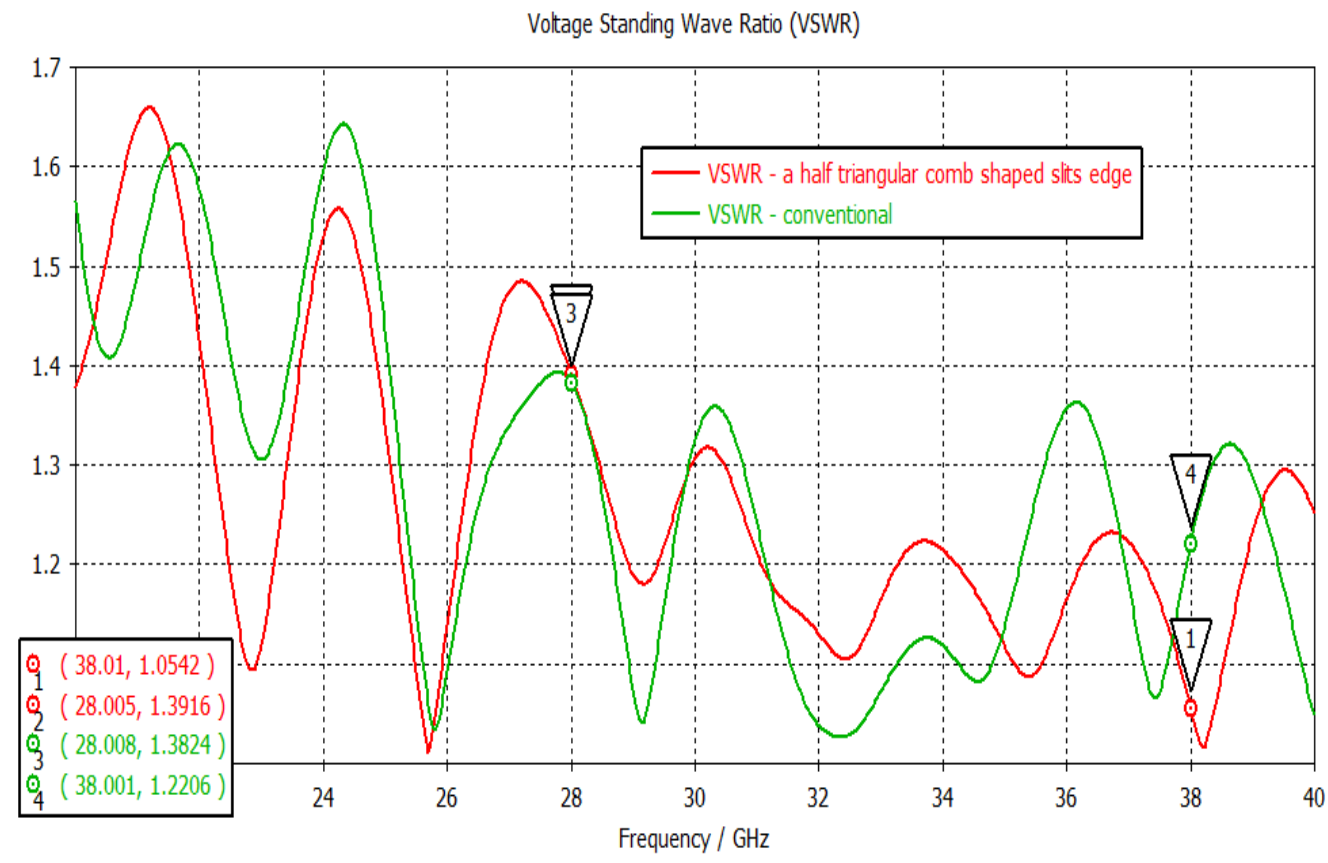

Figure 5. VSWR profile

Table 4. VSWR

\begin{tabular}{ccc}
\hline $\mathrm{F}(\mathrm{MHz})$ & VSWR-conventional & VSWR-a half triangular comb- shaped slits edge \\
\hline 28000 & 1.3824 & 1.3916 \\
38000 & 1.2206 & 1.054 \\
\hline
\end{tabular}

\subsubsection{Radiation Pattern, Directivity/Gain, and H-E Field}

The 3D radiation pattern of Comb-AVA and AVA are shown in Figure 6 and Figure 7. The CombAVA and AVA have a directional radiation pattern with stable radiation. More detail comparison results are shown in Table 5. Based on Figure 6, the comb-AVA creates $9.421 \mathrm{dBi}$ directivity at $28 \mathrm{GHz}$ and $8.58 \mathrm{dBi}$ directivity at $38 \mathrm{GHz}$. In Figure 6 (c), the angular width (3 dB) of comb-AVA at $28 \mathrm{GHz}$ is $107.6^{\circ}$ while the angular width $(3 \mathrm{~dB})$ at $38 \mathrm{GHz}$ is $53.7^{\circ}$.

Based on Figure 7, the AVA creates $8.43 \mathrm{dBi}$ directivity at $28 \mathrm{GHz}$ and $9.14 \mathrm{dBi}$ directivity at 38 GHz which are depicted in Figure 7(a) and Figure (7b), respectively. In Figure 7(c), the angular width (3 dB) of AVA at $28 \mathrm{GHz}$ is $34.3^{\circ}$ while the angular width $(3 \mathrm{~dB})$ at $38 \mathrm{GHz}$ is $21.7^{\circ}$. 


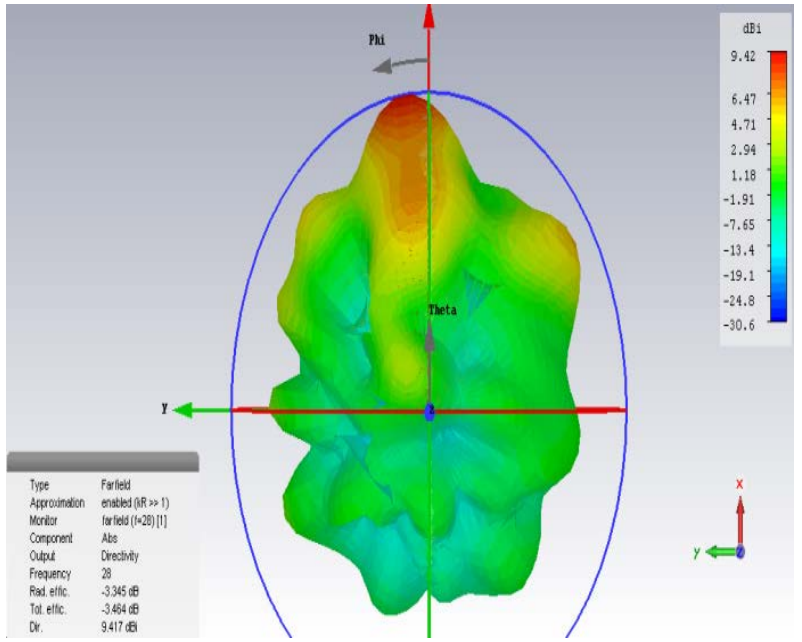

(a) Directivity comb-AVA at $28 \mathrm{GHz}$ (9.42 dBi)

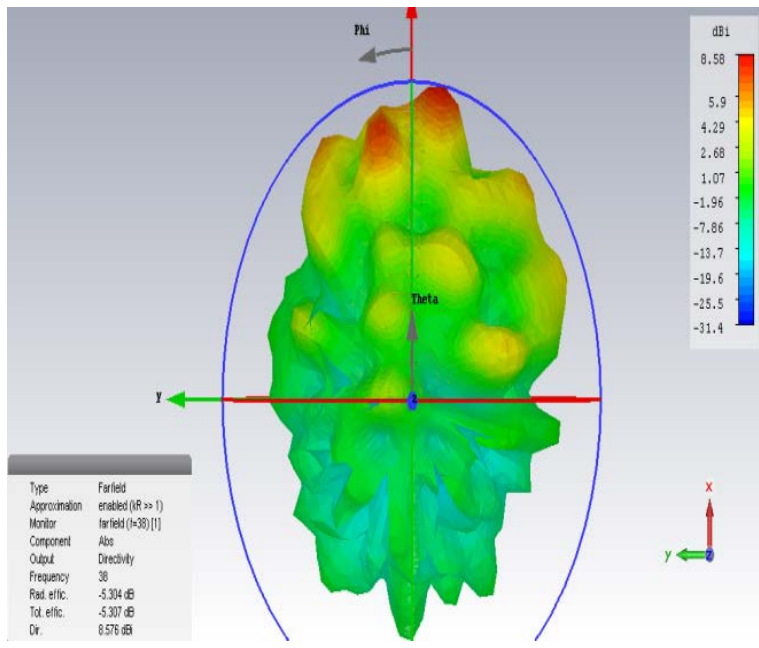

(b) Directivity comb-AVA at $38 \mathrm{GHz}(8.58 \mathrm{dBi})$

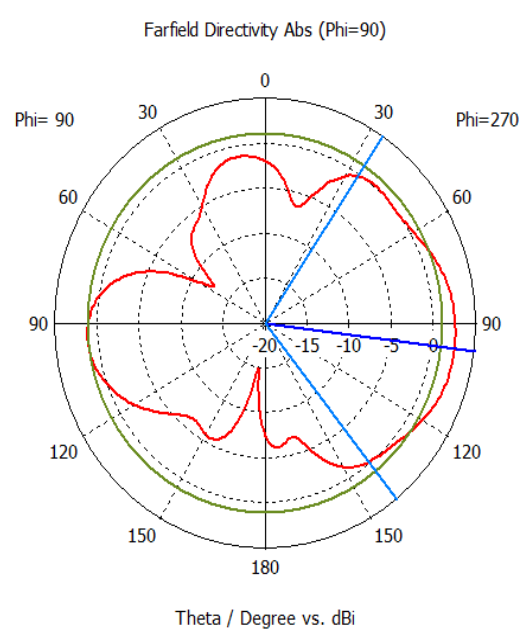

Main lobe magnitude $=2.61 \mathrm{~dB}$

Main lobe direction $=97.0 \mathrm{deg}$.

Angular width $(3 \mathrm{~dB})=107.6 \mathrm{deg}$ Side lobe level $=-1.5 \mathrm{~dB}$

(c) The angular width (3 dB) comb-AVA at $28 \mathrm{GHz}$

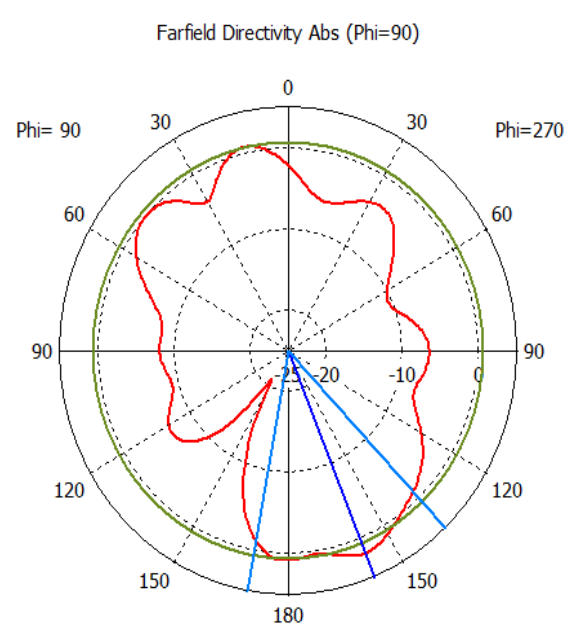

Theta / Degree vs. dBi
— farfield $(f=38)[1]$
Frequency $=38$

Main lobe magnitude $=1.72 \mathrm{~dB}$

Main lobe direction $=158.0$ deg.

Angular width $(3 \mathrm{~dB})=53.7 \mathrm{deg}$. Side lobe level $=-1.1 \mathrm{~dB}$

(d) The angular width (3 dB) comb-AVA at $38 \mathrm{GHz}$

Figure 6. 3D \& 2D radiation pattern of Comb-AVA 


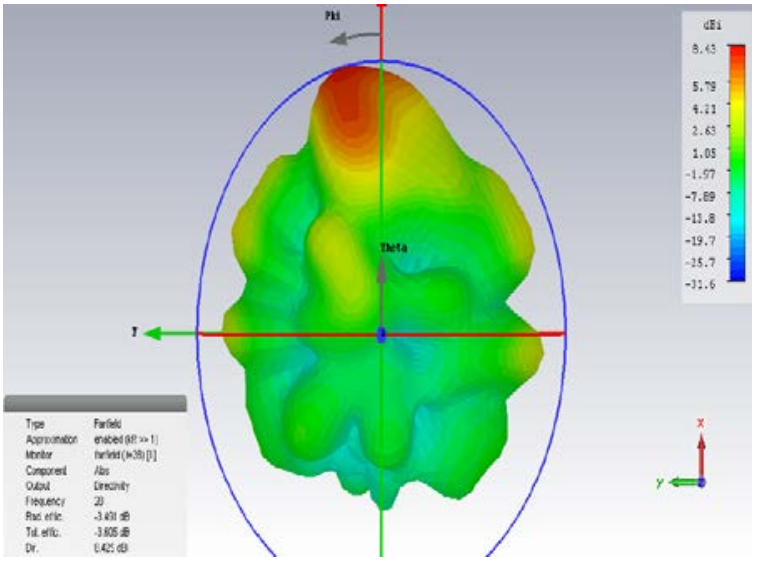

(a) Directivity AVA at $28 \mathrm{GHz}(8.43 \mathrm{dBi})$

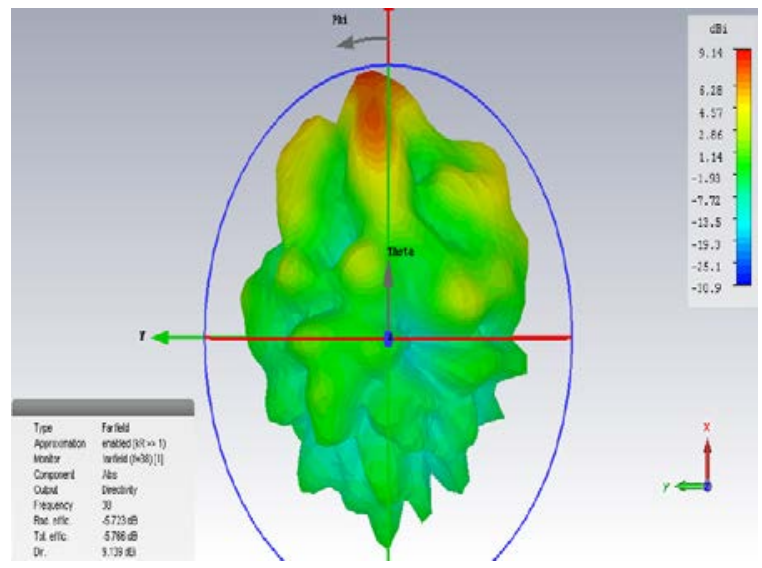

(b) Directivity AVA at $38 \mathrm{GHz}(9.14 \mathrm{dBi})$

Farfield Directivity Abs (Theta $=90$ )

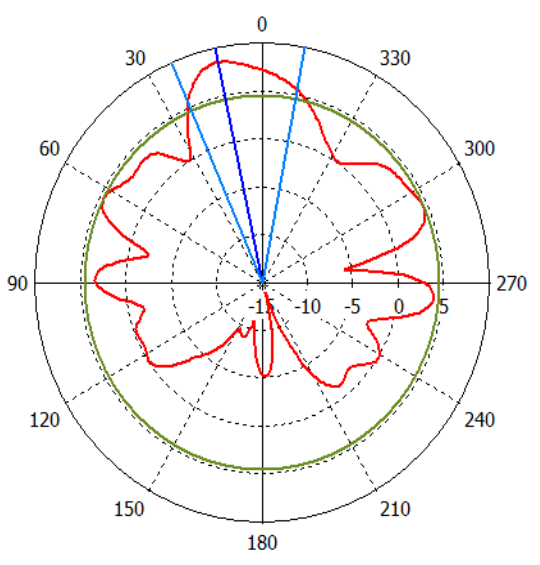

Phi / Degree vs. dBi

- farfield $(f=28)[1]$

Frequency $=28$

Main lobe magnitude $=8.44 \mathrm{dBi}$

Main lobe direction $=12.0 \mathrm{deg}$. Angular width $(3 \mathrm{~dB})=34.3 \mathrm{deg}$. Side lobe level $=-4.0 \mathrm{~dB}$

(c) The angular width (3 dB) AVA at $28 \mathrm{GHz}$

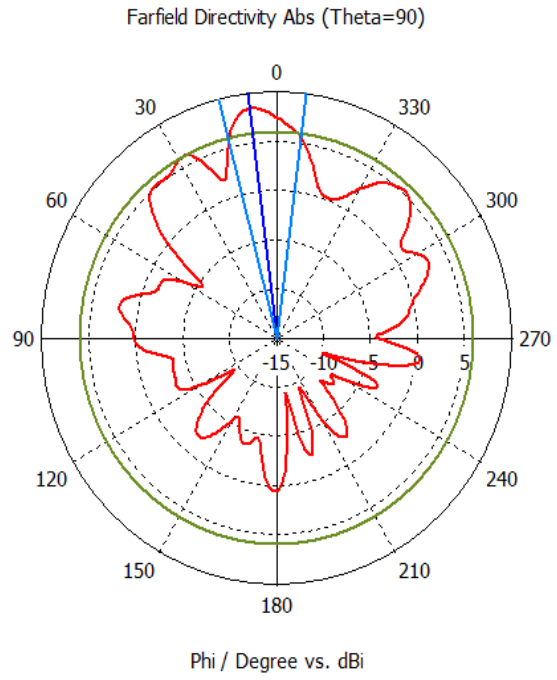

— farfield $(\mathrm{f}=38)[1]$

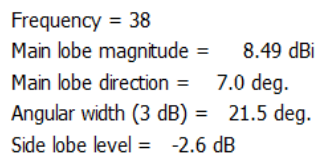

(d) The angular width (3 dB) AVA at $38 \mathrm{GHz}$

Figure 7. 3D \& 2D radiation pattern of AVA (continue) 
Table 5. Comparison Directivity and Angular Width (Comb-AVA \& AVA)

\begin{tabular}{ccccc}
\hline F (MHz) & Directivity-AVA(dBi) & $\begin{array}{c}\text { Directivity-comb AVA } \\
(\mathrm{dBi})\end{array}$ & $\begin{array}{c}\text { Angular width (3 dB) } \\
\text { Comb -AVA }\end{array}$ & $\begin{array}{c}\text { Angular width (3 dB) } \\
\text { AVA }\end{array}$ \\
\hline 28000 & 8.43 & 9.42 & $107.6^{\circ}$ & $34.3^{\circ}$ \\
38000 & 9.14 & 8.58 & $53.7^{\circ}$ & $21.7^{\circ}$ \\
\hline
\end{tabular}

Surface current is an electric current which is induced by an applied electromagnetic field. TLM analyses of the surface current on the top side and on the bottom side of the antenna. Brighter shades indicate areas of high current. Based on Figure 8(a), comb-shaped slits on the edge produces a higher current.

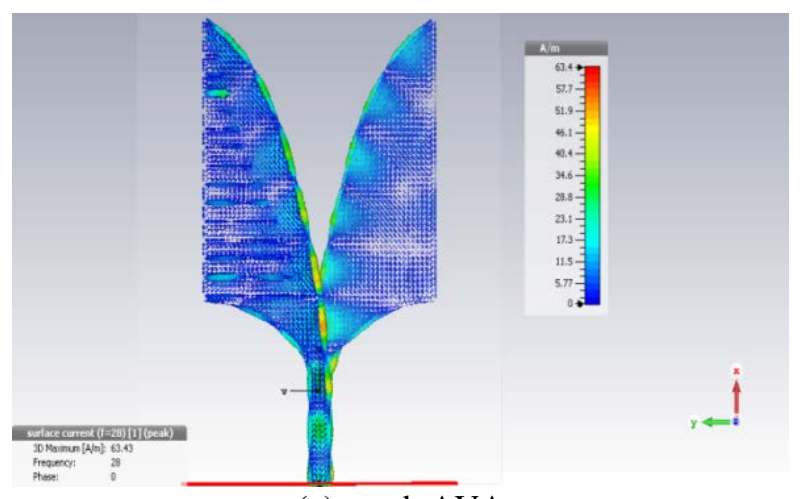

(a) comb AVA

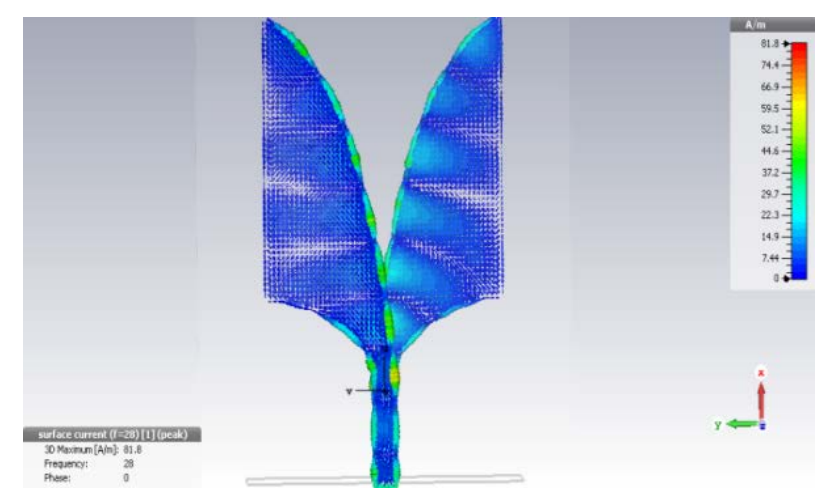

(b) AVA

Figure 8. Surface current

\section{CONCLUSION}

The proposed Comb-AVA is designed to cover 20-40 GHz spectrum. Particularly, it serves dualband 28/38 GHz 5G frequency. The proposed Comb-AVA has the fractional bandwidth (FBW) 0.714 at $28 \mathrm{GHz}$ and 0.526 at $38 \mathrm{GHz}$. FBW $\geq 0.5$, it means that the proposed Comb-AVA supports for UWB technologies including 5G. In addition, it also has impedance bandwidth (S11 $\leq-10 \mathrm{~dB})$ along 20-40 GHz spectrum. The comb-AVA gives better return loss than the AVA at $38 \mathrm{GHz}$ frequency which is $11 \mathrm{~dB}$ refinement. VSWR of the proposed antenna is in range of 1.054 to 1.3916. The Comb-AVA has a wider angular width (3dB) than the AVA. Furthermore, It has higher directivity $(9.42 \mathrm{dBi})$ than AVA (8.43 dBi) at $28 \mathrm{GHz}$, while AVA has higher directivity at $38 \mathrm{GHz}$. This proposed Comb-AVA has good performance and suitable for $5 \mathrm{G}$ technology.

\section{ACKNOWLEDGEMENTS}

The authors would like to acknowledge Directorate Research \& Community Service-Directorate General of Research and Development Strengthening-Indonesian Ministry of Research, Technology and Higher Education for their funding of this research under Applied Research Contract Grant. 


\section{REFERENCES}

[1] P.J. Gibson, "Analysis The Vivaldi Aerial,” $9^{\text {th }}$ European Microwave Conference, 1979.

[2] Igor Minin, "Microwave and Millimeter Wave Technologies Modern UWB antennas and equipment," InTech, 2010.

[3] J. B. Rizk, G. M. Rebeiz, "Millimeter-wave Fermi tapered slot antennas on micromachined silicon substrates," IEEE Transactions on Antennas and Propagation, Vol. 50, No.3, 379-383, Mar. 2002.

[4] Teni, G., N. Zhang, J. H. Qiu, and P. Y. Zhang, "Research on a novel miniaturized antipodal Vivaldi antenna with improved radiation," IEEE Antennas and Wireless Propagat. Lett., Vol. 12, 417-420,2013.

[5] M.De Oliveira, B. Perotoni, Kofuji, Justo,”A Palm Tree Antipodal Vivaldi Antenna With Exponential Slot Edge for Improved Radiation Pattern”, IEEE Antennas And Wireless Propagation Letters, Vol 14, 2015.

[6] J. Wu, Z. Zhau, Z. Nie, and Q.-H. Liu, "A printed UWB Vivaldi antenna using stepped connection structure between slotline and tapered patches,” IEEE Antennas Wireless Propag. Lett., vol. 13, pp. 698-701, 2014.

[7] D.-M. In, M.-J. Lee, D. Kim, C.-Y. Oh, and Y.-S. Kim, "Antipodal linearly tapered slot antenna using unequal halfcircular defected sides for gain improvements,” Microw. Opt. Technol. Lett., vol. 54, no. 8, pp. 1963-1965, Aug. 2012.

[8] S. Pramono, T. Hariyadi, B.B. Subagio, "Performance analysis of transceiver 4 x 4 space time block code MIMOOFDM system," $2^{\text {nd }}$ ICITACEE Conference, 2015.

[9] O. Elijah, et al.," Recent Trend in Electromagnetic Radiation and Compliance Assessments for 5G Communication," International Journal of Electrical and Computer Engineering (IJECE), Vol.7, No.2, pp. 912 918, April. 2017.

[10] L. Ching Yu, M. Ramlee Kamarudin,”5G Fixed Beam Switching on Microstrip Patch Antenna,” International Journal of Electrical and Computer Engineering (IJECE), Vol. 7, No. 2, pp. 975 980, April. 2017.

\section{BIOGRAPHIES OF AUTHORS}
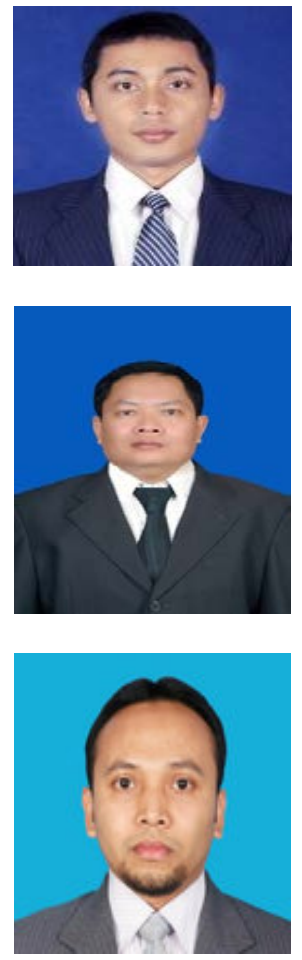

Subuh Pramono received the Bachelor's degree in Telecommunication Engineering from STT Telkom, Bandung, Indonesia, in 2003, and the Master's degree in Elecrical Engineering from Institut Teknologi Bandung (ITB), Bandung, Indonesia, in 2009. He has published many journal papers and conference proceedings. He is currently a lecturer at Department of Electrical Engineering, Faculty of Engineering, Universitas Sebelas Maret Surakarta-Indonesia. His research interests are wireless and mobile communications, antenna and propagation, SAR (synthetic aperture radar).

Budi Basuki Subagio received the Bachelor's degree in Electrical Engineering from Universitas Brawijaya, Indonesia, in 1996, and the Master's degree in Electrical Engineering from Universitas Gajah Mada, Yogyakarta, Indonesia, in 2012.. He is currently a lecturer at the Electrical Engineering Department, Politeknik Negeri Semarang. His research interests is antenna system.

Tommi Hariyadi received the Bachelor's degree and Master's degree in Electrical Engineering from Institut Teknologi Bandung (ITB),Bandung, Indonesia, in 2005 and 2009. He has published many journal papers and conference proceedings. He is currently a lecturer at Department of Electrical Engineering, Universitas Pendidikan Indonesia, Bandung, Indonesia. His research interests are antenna and propagation, microwave engineering, radar. 